\title{
Epidemiology of Type 1 (Insulin-Dependent) Diabetes in Scotland 1968-1976: Evidence of an Increasing Incidence
}

\author{
C.C.Patterson ${ }^{1}$, M.Thorogood ${ }^{2}$, P. G. Smith ${ }^{1}$, M.A. Heasman ${ }^{3}$, J.A. Clarke ${ }^{3}$ and J. I. Mann ${ }^{2}$ \\ ${ }_{1}^{1}$ Department of Medical Statistics and Epidemiology, London School of Hygienë and Tropical Medicine, London, \\ ${ }^{2}$ Department of Community Medicine and General Practice, University of Oxford, Radcliffe Infirmary, Oxford and \\ ${ }^{3}$ Scottish Health Service Common Services Agency, Edinburgh, UK
}

\begin{abstract}
Summary. A computer file of all Scottish hospital admissions in the period 1968-1976 was searched to identify the 2,505 children (aged $<19$ years) with a diagnosis of diabetes. The average annual incidence of the disease (based on first hospital admission) was estimated to be 13.8 per 100,000 children aged $<19$ years (boys 14.4 per 100,000 ; girls 13.2 per 100,000 ). The highest incidence, 20.0 per 100,000 was in the age group $10-14$ years and the lowest 7.1 per 100,000 in those aged $<5$ years. It is estimated that during the study period there was an $80 \%$ increase in the annual incidence of juvenile diabetes, from about 10 per 100,000 in 1968 to about 18 per 100,000 in 1976. First admission rates showed seasonal variations for those aged 5 years or more, with peaks in October/November and January/February. Marked variation was found in the incidence rates in the different counties of Scotland. The central lowlands which includes the cities of Edinburgh and Glasgow
\end{abstract}

was an area of low incidence. There appeared to be an inverse correlation between the incidence rate in each county and population density. In Glasgow, there was an inverse association between the incidence rate in each city ward and the average number of persons per room. There was no evidence of space-clustering of the disease in different years within the parishes (rural districts) of each county and there was no convincing evidence that the variation in the incidence of diabetes between parishes in the same county was more than might have been expected to arise by chance. The observations are compatible with the disease having a viral aetiology but it is difficult to explain the striking rise in incidence over the study period on this basis.

Key words: Diabetes, juvenile, incidence, Scotland, seasonal variation, population density, age of onset.
There is circumstantial evidence suggesting that viral infections play a role in the aetiology of Type 1 (insulindependent) diabetes. There are several reports of children in the same family developing the disease at about the same time [1]. A fairly consistent pattern has been noted in the seasonal variation in the month of onset of Type 1 diabetes, with peaks in the autumn and winter [2]. Furthermore, the incidence peaks around the age of 5 years, when children commonly start primary education, and 12 years, the age when children often change schools to start their secondary education. At both these ages children are likely to be exposed to a new environment and may acquire new infections. Coxsackie B 4 virus has been suggested as a possible aetiological agent. Children with newly diagnosed diabetes were found to have higher antibody titres to this virus than long-standing diabetics or normal subjects [3]. Yoon et al. [4] found a variant of Coxsackie B 4 virus in the pancreas of an 11 year old boy who died from diabetic ketoacidosis.
The virus caused diabetes when injected into certain strains of mice.

The incidence of the disease has been reported to vary markedly from year to year and in different areas of the British Isles [1], but this finding is difficult to interpret as the results were based on notifications of new cases received during the first 2 years of a national voluntary register. There might have been variation in the completeness of reporting in different areas and at different times. A study of Type 1 diabetes in an English county (Oxfordshire) showed considerable variations in incidence rates between different health districts and a striking cluster of children with the disease was found within a single parish in one district [5].

The present investigation was undertaken to determine if previously reported epidemiological observations could be confirmed in a study based on all cases of the disease notified in Scotland over a 9-year period. We were especially interested in examining the distribu- 
Table 1. Age and sex specific average annual incidence rates of diabetes (corrected for readmissions)

\begin{tabular}{lccc}
\hline $\begin{array}{l}\text { Age at first } \\
\text { admission (years) }\end{array}$ & \multicolumn{3}{l}{$\begin{array}{l}\text { Corrected average annual } \\
\text { incidence rate (per 100,000) }\end{array}$} \\
\cline { 2 - 4 } & Male & Female & Total \\
\hline $0-4$ & 7.3 & 6.8 & 7.1 \\
$5-9$ & 12.0 & 10.8 & 11.4 \\
$10-14$ & 20.0 & 20.1 & 20.0 \\
$15-18$ & 19.6 & 15.3 & 17.5 \\
\hline $0-18$ & 14.4 & 13.2 & 13.8 \\
\hline
\end{tabular}

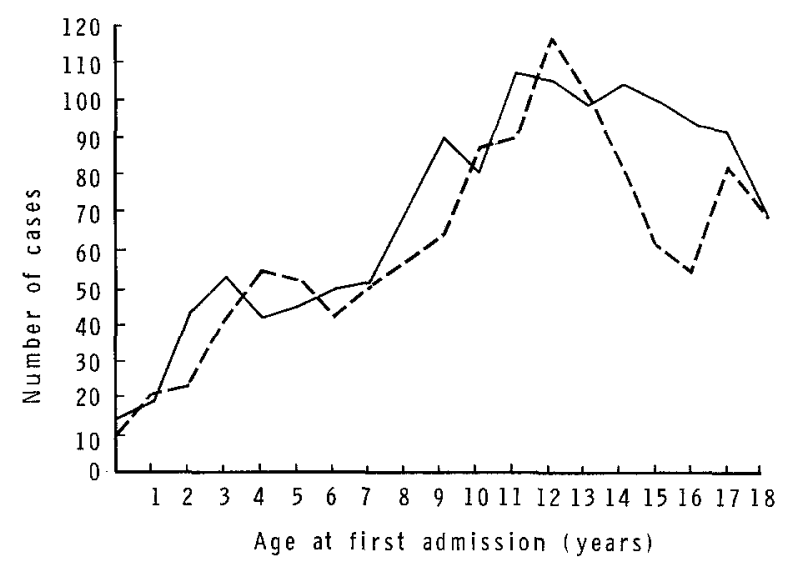

Fig. 1. Age of children when first admitted to hospital with diabetes during 1968-1976. (— males, ---- females)

tion of the disease for evidence of clustering in space or in time or in space and time jointly.

\section{Methods}

Since 1968 details of all non-psychiatric in-patient discharges from Scottish hospitals have been recorded on computer. The system has been described by Heasman [6] and Heasman and Clarke [7]. Records for the period 1968-1976 were searched to identify all children under the age of 19 years who had a discharge diagnosis of diabetes. For each of the 7,197 admissions so identified, the surname of the patient was extracted together with his or her initials, sex, date of birth, date of admission and area of residence. These records were arranged in alphabetical order (and subsequently in date of birth order and by area of residence) and this enabled $4,482(62.3 \%)$ to be removed as they were found to relate to readmissions of patients already included (the routine recording system does not distinguish first admissions from subsequent admissions with the same condition). A computer file of school medical examinations for the period 1967-1976 was also searched and 861 children identified who had been noted to have diabetes at a school medical inspection. Since neither area of residence nor date of first hospital admission were recorded for these children, the data were used only as a means of identifying children known to have diabetes before their first recorded hospital admission. Eightyone children were excluded from the hospital series on this basis (the date of first recorded hospital admission being after the date of the school medical inspection at which diabetes was noted). A further 86 cases, whose date of admission with diabetes was recorded as in the first month of life were excluded from the series (most were coding errors - diabetes in the mother had been wrongly coded as diabetes in the newborn child) and 43 patients were excluded who lived outside Scotland. The remaining 2,505 children constitute the study series.

For each child we had a record of their date of first hospital admission with diabetes in the period 1968-1976, their age, sex and usual place of residence. Place of residence was coded according to Scottish county and to rural parish or city ward within the County, these being the smallest areas for which population estimates are available. Twenty-four cases were excluded because place of residence was unknown. A further 135 cases could only be included in analyses at a county level since we were unable to determine their parish.

Parish and city ward populations (by sex in individual years of age up to 18 years) were supplied by the General Register Office for Scotland from the 1971 census. These populations have been used to estimate the average annual incidence rates of diabetes for cases diagnosed during 1968-1976. For the calculation of annual rates the Register General's mid-year population estimates were used.

In testing our data for seasonal variation in admission rates two statistical tests were used. One was based on Edward's test [8] which is appropriate when a sinusoidal pattern of incidence with a single peak is expected during a year [9] and the other was a non-parametric procedure for which no assumptions are made about the form of any seasonal variation [10]. Tests for the detection of clustering of cases in small areas [11] and of space-time clustering [12] were also used as well as a test for a linear trend in proportions [13].

Since we could not determine if a child's first hospital admission with diabetes during the period of 1968-1976 was in fact the first ever admission with diabetes (as we had no information on admissions before 1968), it was necessary to develop a method that enabled us to estimate the proportion of children in our study who had been admitted to hospital with diabetes before 1968. Children whose first recorded admission during the period 1968-1976 was in 1976 were unlikely to have been admitted before 1968 (as we knew they had not been admitted in the period 1968-1975). However, those children whose first recorded admission was in the earlier years of our study were more likely to have been admitted before 1968 since we were able to check for previous admissions only back to 1968 (e.g. for those first admitted in 1969 we could only be sure that they had not been admitted in 1968). The method developed to calculate correction factors to adjust for readmissions for each of the years 1968-1976 is given in the Appendix.

\section{Results}

Of the 2,505 children $1,337(53.4 \%)$ were boys and 1,165 $(46.5 \%)$ girls (for three the sex was not recorded). Figure 1 shows the age distribution at the time of first admission during 1968-1976. For the boys there is a small peak in the number of cases at the age of 3 years and another at 11 years and, for the girls there are peaks at 4 years and 12 years. Age and sex specific average annual incidence rates are given in Table 1 . (These rates are based on admission rates and have been corrected to eliminate the effect of readmissions using the method described in the Appendix*). Incidence rates among boys were slightly higher than those among girls except at age 10-14 years. For both sexes the highest rate was in the age group 10-14 years. The estimated average annual incidence rate of diabetes, for all ages combined (0-18 years), was 13.8 per 100,000 .

The estimated incidence rates in each year of the study period are given in Table 2 . Both uncorrected and

\footnotetext{
* The same correction factors were used for all age groups and for both sexes.
} 
Table 2. Age standardised and corrected ${ }^{\mathrm{a}}$ age standardised annual incidence rates

\begin{tabular}{|c|c|c|c|c|c|c|}
\hline \multirow[t]{2}{*}{ Year } & \multicolumn{3}{|c|}{$\begin{array}{l}\text { Standardised annual } \\
\text { incidence rate } \\
\text { per } 100,000\end{array}$} & \multicolumn{3}{|c|}{$\begin{array}{l}\text { Corrected standardised } \\
\text { annual incidence rate } \\
\text { per } 100,000\end{array}$} \\
\hline & Male & Female & Total & Male & Female & Total \\
\hline 1968 & 22.2 & 21.3 & 21.8 & 10.2 & 9.8 & 10.0 \\
\hline 1969 & 18.5 & 15.9 & 17.2 & 12.0 & 10.3 & 11.2 \\
\hline 1970 & 14.9 & 17.5 & 16.2 & 11.3 & 13.3 & 12.3 \\
\hline 1971 & 16.4 & 13.6 & 15.1 & 13.8 & 11.4 & 12.7 \\
\hline 1972 & 15.6 & 14.7 & 15.2 & 14.2 & 13.4 & 13.8 \\
\hline 1973 & 16.8 & 15.1 & 16.0 & 16.0 & 14.3 & 15.2 \\
\hline 1974 & 15.5 & 14.3 & 14.9 & 15.0 & 13.9 & 14.5 \\
\hline 1975 & 18.0 & 14.8 & 16.4 & 17.5 & 14.4 & .15 .9 \\
\hline 1976 & 19.6 & 17.3 & 18.5 & 19.4 & 17.1 & 18.3 \\
\hline $1968-76$ & 17.5 & 16.1 & 16.8 & 14.4 & 13.2 & 13.8 \\
\hline
\end{tabular}

a See Appendix

Table 4. Average annual incidence rate ${ }^{a}$ by population density in Glasgow City Wards

\begin{tabular}{llll}
\hline $\begin{array}{l}\text { Population density } \\
\text { (persons/room) }\end{array}$ & \multicolumn{3}{l}{$\begin{array}{l}\text { Average annual incidence rate } \\
\text { (per 100,000) }\end{array}$} \\
\cline { 2 - 4 } & Male & Female & Total \\
\hline$<0.8$ & 14.9 & 13.1 & 14.0 \\
$0.8-$ & 10.0 & 11.7 & 10.8 \\
$0.9-$ & 11.6 & 8.7 & 10.2 \\
$1.0-$ & 8.7 & 8.3 & 8.5 \\
1.1 or more & 7.3 & 8.9 & 8.2 \\
\hline Overall & 10.4 & 9.9 & 10.2 \\
\hline$\chi^{2}$ test for & 6.4 & 2.9 & 8.5 \\
trend $(1 \mathrm{df})$ & $(p=0.01)$ & & $(p<0.01)$ \\
\hline
\end{tabular}

a Not corrected for readmissions

corrected rates are given and all rates have been standardised to the 1971 census population. The uncorrected rates show no clear trend with time but the corrected rates increase steadily over the study period (Fig. 2). Overall there is a rise of about $90 \%$ for boys and $70 \%$ for girls between 1968 and 1976.

Admission rates were higher in the winter months than in the summer months. Figure 3 shows the number of cases ('first') admitted in each month separately for children aged 0-4 years, 5-11 years and 12-18 years. Statistically significant seasonal variation was apparent only in those aged 5 years and above $(p<0.05)$, with peaks in October/November and January/February. The monthly variation in the rates for those aged $<5$ years was not statistically significant.

The average annual incidence rates by county (uncorrected for readmissions) range from 8.5 per 100,000 in Peebles to 34.1 per 100,000 in Sutherland and the variation between the different counties was highly significant $\left(\chi^{2}(35 \mathrm{df})=165.5 ; p<0.001\right)$. There appeared to be an area of relatively low incidence through-out the central lowlands. It was notable that the rate in Glasgow,
Table 3. Average annual incidence rate ${ }^{\mathrm{a}}$ by population density in the counties of Scotland

\begin{tabular}{llll}
\hline $\begin{array}{l}\text { Population density } \\
\text { (persons/hectare) }\end{array}$ & \multicolumn{3}{l}{$\begin{array}{l}\text { Average annual incidence rate } \\
\text { (per 100,000) }\end{array}$} \\
\cline { 2 - 4 } & Male & Female & Total \\
\hline$<0.2$ & 24.4 & 20.1 & 22.3 \\
$0.2-$ & 23.2 & 19.4 & 21.4 \\
$1.0-$ & 16.8 & 16.6 & 16.7 \\
$3.0-$ & 17.1 & 15.6 & 16.4 \\
10.0 or more & 13.2 & 12.2 & 12.7 \\
\hline Overall & 17.4 & 15.8 & 16.6 \\
\hline$\chi^{2}$ test for & 52.3 & 32.5 & 84.3 \\
trend $(1 \mathrm{df})$ & $(p<0.001)$ & $(p<0.001)$ & $(p<0.001)$ \\
\hline
\end{tabular}

a Not corrected for readmissions

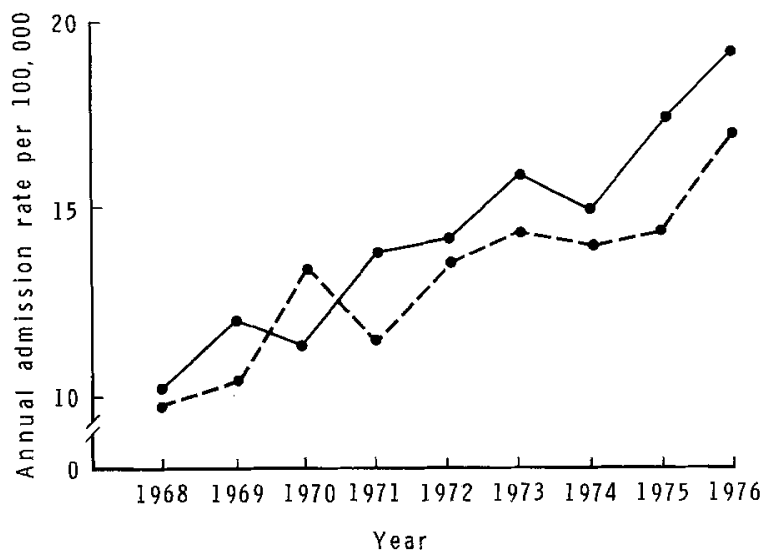

Fig. 2. Corrected age standardised annual admission rates during 1968-1976. (- males, females)

the largest city in Scotland was relatively low (10.2 per 100,000 per year).

To determine if there was evidence of any clustering of cases in parishes, within counties or in wards within cities, the distribution of cases (using address at first recorded admission) in each of the 967 parishes or city wards in Scotland was examined. The test for clustering was applied within each county and the results summed. In a few counties there was some evidence of clustering but, when the data were considered as a whole, there was no evidence that the variation in the incidence rates between areas within counties was more than might have been expected to arise by chance.

The incidence rates appear to be highest in those areas of the country that are most sparsely populated. Using data from the 1971 census, the counties were divided into five categories on the basis of their population densities (Table 3). Incidence data from counties with population densities in the same category were combined and the results are summarised in Table 3. For both boys and girls there was a progressive increase in incidence rates as population densities decrease and 


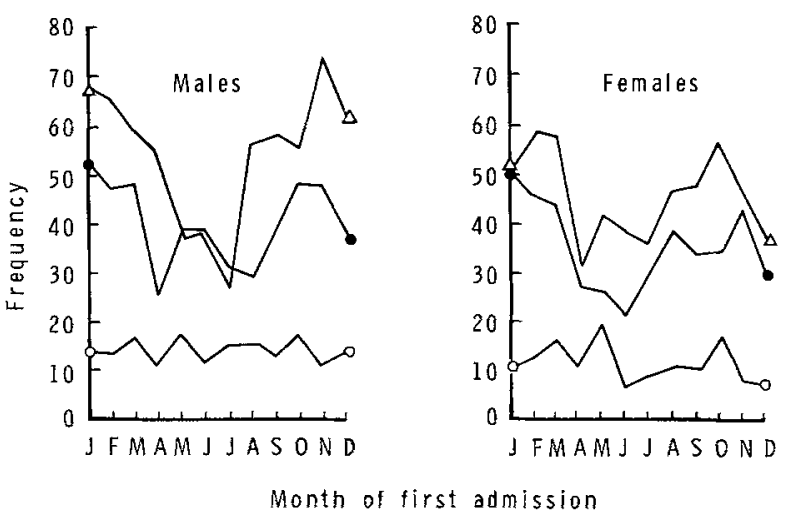

Fig. 3. Numbers of boys and girls first admitted with diabetes in different months ages $0-4(\mathrm{O}-\mathrm{O}), 5-11(-\mathrm{C})$ and $12-18$ years $(\Delta-\Delta)$

for each sex the trend was highly significant $(p<0.001)$. To investigate whether this might be due to differences in readmission patterns in areas of high and low population density we repeated the analysis shown in Table 3 for the data from the period 1974-1976 (when the effects of readmissions were minimal - see Appendix). Significant trends were still apparent for each sex $(p<$ $0.01)$ though the admission rates in the lowest population density categories were less than those shown in Table 3.

To determine if such an association existed in a small area and where the disease incidence was lower, data from the city wards in Glasgow were analysed in a similar fashion. No association was found between population density (as measured by persons per hectare) and diabetes incidence, but when the wards were categorised on the basis of the average number of persons per room in the ward, as given in the 1971 census, there was an inverse relationship between the average number of persons per room and the incidence of diabetes (Table 4).

Evidence of space-time clustering was sought by examining the year-to-year variation in the number of first admissions from each parish or ward in the years 1970-74 (a period during which the national average annual incidence rate, not corrected for readmissions (Table 2), was relatively stable). There was no evidence of space-time clustering.

\section{Discussion}

Our survey of Type 1 diabetes (first diagnosed $<19$ years of age) is one of the largest epidemiological studies to have been conducted on this disease. It was made possible by use of the register of all hospital admissions, which has been maintained on computer for the whole of Scotland since 1968. There were two drawbacks in using these data for an epidemiological investigation.

Firstly, our analysis necessarily excluded those children who developed diabetes but who were not admit- ted to hospital. We do not think that this is a serious source of bias since Scottish diabetologists and paediatricians have confirmed that throughout the period of study it was their policy to admit newly diagnosed cases to hospital. Furthermore, the average annual incidence of diabetes we observed during the study period, 13.8 per 100,000 children aged $0-18$ years, is higher than the corresponding rates of 7.4 per 100,000 estimated for Scotland [1] during 1973-74 and is also higher than the rate of 10.1 per 100,000 obtained for Oxfordshire [5] for the period 1969-76. The rates are rather similar to those observed by Christau et al. in Denmark [14].

Secondly, the computer record of each admission contains no information on whether or not it relates to the first or to a subsequent admission. We found that many children had been admitted more than once with diabetes and it was necessary to devise a method which allowed us to determine the effect that readmissions may have had on our estimates of incidence of new cases. The method we used is detailed in the Appendix.

The $80 \%$ increase in incidence of the disease over a 9 -year period is striking. This apparent increase is not due to a general increase in the total number of patients recorded by the Scottish Inpatient system. During the period 1968-76, the total recorded admissions (for all causes) among children aged $0-14$ years in fact declined slightly (Heasman, personal communication). It is possible that the assumptions we made in deriving incidence rates adjusted for readmissions may have overestimated this trend but it seems most unlikely that this could account for all the change observed. A very conservative estimate based on extrapolation from Appendix Figure A1 suggests that the real increase in incidence cannot be less than 30\% during the period 1968-1976. We have no explanation for this increase but our finding supports an earlier observation of a $70 \%$ increase in the number of newly diagnosed cases of diabetes treated at the Royal Hospital for Sick Children in Glasgow between 1969-1972 and 1973-1976. These observations suggest that trends in incidence after 1976 $[15,16]$ should be carefully monitored to determine if they have continued to rise.

Our study has confirmed a previous report [3] that children over 5 years of age are more likely to be admitted to hospital with diabetes in late autumn or winter. The apparent peaks in hospital admission are not very marked, and do not provide strong support for the suggestion that peaks of incidence occur at the time of starting school (or kindergarten) and changing schools. The peaks are at different ages for boys and girls and the early peaks occur at ages which seem to be too young to be related to starting school. State organised nursery education in Scotland was uncommon during the study period.

Considerable differences in the incidence rates of juvenile diabetes in districts of Oxfordshire have been reported [5] and we have confirmed that there is considerable geographical variation in admission rates. Rates 
Table A1. Proportion of total admissions in 1976 classified as readmissions on the basis of a previous admission in an earlier year during the study period

\begin{tabular}{|c|c|c|c|c|}
\hline $\begin{array}{l}\text { Index } \\
\mathrm{j}\end{array}$ & $\begin{array}{l}\text { Year } \\
\mathbf{x}\end{array}$ & $\begin{array}{l}\text { Number of } \\
\text { patients } \\
\text { with } \\
\text { admission } \\
\text { in year } x \\
\text { and in } 1976^{\mathrm{a}}\end{array}$ & $\begin{array}{l}\text { Number of patients } \\
\text { admitted in } 1976 \text { who } \\
\text { were classed as read- } \\
\text { missions because of } \\
\text { admissions in year x } \\
\text { of later year }\end{array}$ & $\begin{array}{l}\text { As } \\
\text { proportion } \\
\text { of total } 1976 \\
\text { admissions } \\
\left(r_{j}\right)\end{array}$ \\
\hline 0 & 1976 & $(696)$ & - & 0.000 \\
\hline 1 & 1975 & 202 & 202 & $0.290^{a}$ \\
\hline 2 & 1974 & 73 & 275 & 0.395 \\
\hline 3 & 1973 & 42 & 317 & 0.455 \\
\hline 4 & 1972 & 26 & 343 & 0.493 \\
\hline 5 & 1971 & 16 & 359 & 0.516 \\
\hline 6 & 1970 & 6 & 365 & 0.524 \\
\hline 7 & 1969 & 1 & 366 & 0.526 \\
\hline 8 & 1968 & 8 & 374 & 0.537 \\
\hline
\end{tabular}

${ }^{a}$ Patients are not counted in a particular year if they have also been admitted in a later year (before 1976). Thus for example 275 patients $(202+73)$ who were admitted in 1976 were also admitted in 1975 or 1974. b Equals 202/696

Table A2. Correction factors to convert the number of 'apparent' first admissions in each year of the study period to the estimated number of 'true' first admissions

\begin{tabular}{lll}
\hline $\begin{array}{l}\text { Index } \\
\mathrm{i}\end{array}$ & Year of study & $\begin{array}{l}\text { Correction factor } \\
\left(\mathrm{c}_{\mathrm{i}}\right)\end{array}$ \\
\hline 1 & 1968 & 0.46 \\
2 & 1969 & 0.65 \\
3 & 1970 & 0.76 \\
4 & 1971 & 0.84 \\
5 & 1972 & 0.91 \\
6 & 1973 & 0.95 \\
7 & 1974 & 0.97 \\
8 & 1975 & 0.97 \\
9 & 1976 & 0.99 \\
\hline & $1968-1976$ & 0.82 \\
\hline
\end{tabular}

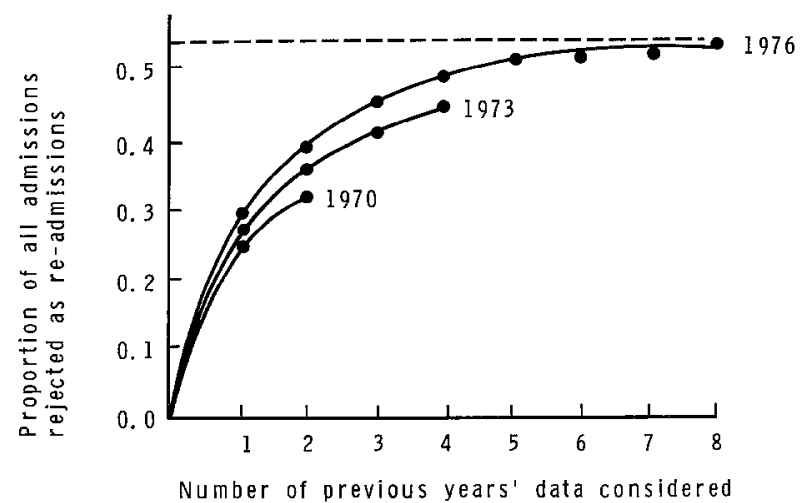

Fig. A1. Proportion of all admissions rejected as re-admissions by the number of previous years information considered

in the two northern counties of Scotland are three times as high as in Glasgow and twice as high as in Edinburgh and, in general, there seems to be an inverse association between admission rates for diabetes and population density. A similar association has been observed among Swedish children with diabetes [17], though the situa- tion is less clear in Denmark [14]. Failure to find evidence of space-clustering suggests that there is no simple relationship between infection and onset of Type 1 diabetes. The apparent large increase in incidence over the study period also cannot readily be explained on the basis of an infectious aetiology. However, the finding of a higher incidence in sparsely populated areas may be compatible with an aetiology similar to that of infectious mononucleosis and paralytic polio, that is delayed infection with a common virus. The higher incidence after the age of 10 years would also be consistent with such an hypothesis.

\section{References}

1. Bloom A, Hayes TM, Gamble DR (1975) Register of newly diagnosed diabetic children. Br Med J 3: 580-583

2. Gamble DR, Taylor KW (1969) Seasonal incidence of diabetes mellitus. Br Med J 3: 631-633

3. Gamble DR, Kinsley ML, Fitzgerald MG, Bolton R, Taylor KW (1969) Viral antibodies in diabetes mellitus. Br Med J 3: 627-630

4. Yoon JW, Austin M, Onodera T, Notkins AL (1979) Virus induced diabetes mellitus: isolation of a virus from the pancreas of a child with diabetic ketoacidosis. New Engl J Med 300: 1173-1179

5. Mann JI, Thorogood M, Smith PG (1978) Space clustering of juvenile onset diabetes. Lancet 1:1369-1370

6. Heasman MA (1968) Scottish hospital in-patient statistics sources and uses. Health Bulletin 26:10-18

7. Heasman MA, Clarke JA (1979) Medical record linkage in Scotland. Health Bulletin 37: 97-103

8. Edwards JH (1961) The recognition and estimation of cyclic trend. Ann Hum Genet 25: 83-86

9. Walter SD, Elwood JM (1975) A test of seasonality of events with a variable population of risk. Br J Prev Soc Med 29: 18-21

10. Freedman LS (1978) The use of a Kolmogorov-Smirnov type statistic in testing hypotheses about seasonal variation. J Epidemiol Community Health $33: 223-228$

11. Walter SD (1974) On the detection of the household aggregation of disease. Biometrics. 30: 525-538

12. Ederer F, Myers MH, Mantel N (1964) A statistical problem in space and time: do leukemia cases come in clusters? Biometrics 20:626-638

13. Armitage $\mathbf{P}(1955)$ Tests for linear trend in proportions and frequencies. Biometrics 11: 375-386

14. Christau B, Kromann H, Ortved Anderson O, Christy $M$, Buschard K, Arnung K, Hojland Kristensen I, Peitersen B, Steinrud J, Nerup J (1977) Incidence, seasons and geographic patterns of juvenile onset insulin-dependent diabetes mellitus in Denmark. Diabetologia 13: 281-284

15. Craig JOl, Ford JA, McCuish AC (1977) Rising incidence of childhood diabetes. Br Med J 1: 639

16. Scott-Samuel A (1977) Rising incidence of childhood diabetes. $\mathrm{Br}$ Med J 1: 840

17. Sterky G, Holmgren G, Gustavson KH, Larsson Y, Lundmark KM, Nilsson KO, Samuelson G, Thalme B, Wall S (1978) The incidence of diabetes mellitus in Swedish children. Acta Paediatr Scand 67: 139-143

Received: 14 December 1981

and in revised form: 13 September 1982

Dr. J. I. Mann

Department of Community Medicine

and General Practice

University of Oxford

Radcliffe Infirmary

Oxford, UK 


\section{Appendix}

\section{Adjustment for Readmissions}

The total number of patients admitted to hospital for jivenile diabetes in any one year is made up of two groups - those admitted for the first time with the disease and those first admitted with the disease in a previous year who are readmitted for further investigations or treatment. In studying the incidence of the disease we are interested only in the former group but the data available to us on each admission did not enable us to determine directly if it was the first or a subsequent admission with diabetes. We could, however, inspect the list of admissions in preceding years, back to 1968 , to determine if a child had also had an admission in one of those previous years. For example, in 1976, our original list consisted of 696 children admitted with diabetes. Two hundred and two of these had also been admitted in 1975 and 73 had been admitted in 1974 (but not in 1975) and eight had been admitted in 1968 (but not in 1969-1975) (Table A1). Thus, by considering only one previous year we were able to reject $29 \%(202 / 696)$ of the 1976 cases as having been admitted before and by considering the admissions in the 8 preceding years we were able to reject $54 \%$ (374/696) of the 1976 cases as having been previously admitted. This is shown graphically in Figure A1. It may be seen (Table A1, Fig. A1) that only $15(2.2 \%)$ of the 696 admissions in 1976 were detected as readmissions because of admissions in the period 6-8 years before 1976 (i.e. 1968-1970). Thus it seems likely that the 322 patients (=696-374) whose admission in 1976 was their only admission in the period 1968-1976 will include very few patients who were first admitted before 1968 .

If we assume that the ratio of number of first admissions to the number of readmissions remained constant for each of the years 1968-1976, we may use Figure A1 to calculate 'correction factors' which may be used to estimate the number of first admissions in each of these years.

Let $t_{i}$ be the total number of admissions in the $i$ th year

$(i=1=1968 ; i=2=1969 ; \ldots ; i=9=1976)$

Let $\mathrm{f}_{\mathrm{i}}$ be the number of first admissions in the $\mathrm{i}$ th year

Assume

$f_{i}=\alpha t_{i}($ for all $i)$ (where $\alpha$ is a constant)
Let $n_{i}$ be the number of 'apparent' first admissions in the $i$ th year. That is, the number admitted in year $i$ who had not been admitted in year $1,2, \ldots$, or $\mathrm{i}-1$.

If the proportion of total admissions in a year which are rejected as being readmissions is $r_{j}$ when $j$ years previous data are available, we have

$\mathrm{n}_{\mathrm{i}}=\mathrm{t}_{\mathrm{i}}\left(1-\mathrm{r}_{\mathrm{i}-1}\right) \quad\left(\right.$ where $\left._{\mathrm{o}}=0\right) \quad \mathrm{i}=1,2, \ldots 9$

Thus, from (1) and (2), we have

$\mathrm{f}_{\mathrm{j}}=\alpha \mathrm{n}_{\mathrm{i}} /\left(1-\mathrm{r}_{\mathrm{i}-1}\right)$

$=\mathrm{c}_{\mathrm{i}} \mathrm{n}_{\mathrm{i}} \quad$ where $\mathrm{c}_{\mathrm{i}}=\alpha /\left(1-\mathrm{r}_{\mathrm{i}-1}\right)$

From Figure A1 it appears that as the number of previous years data available increases the proportion of cases that are rejected as having been previously admitted tends towards an asymptotic value of about 0.54 . At the asymptotic value $\mathrm{f}_{\mathrm{j}}=\mathrm{n}_{\mathrm{i}}$ (i.e. all 'apparent' first admissions are 'true' first admissions) and thus we may estimate $\alpha$ to be 0.46 . The graph shown in Figure A1 enables us to estimate $r_{i}$ for $\mathrm{i}=1,2, \ldots, 8$ and thus, using (3), we can estimate the correction factors $\mathrm{c}_{\mathrm{i}}$. These are shown in Table $2 \mathrm{~A}$. We have used the correction factors shown in Table $2 \mathrm{~A}$ to adjust the number of 'apparent' first admissions in each of the years of the study to obtain an estimate of the actual numbers of first admissions in each year. The overall correction factor at the foot of the table was obtained as a weighted mean of the correction factors for the individual years, using the numbers of apparent first admissions in each year as weights.

$c_{\text {overall }}=\frac{\sum \mathrm{n}_{\mathrm{i}} \mathrm{c}_{\mathrm{i}}}{\Sigma \mathrm{n}_{\mathrm{i}}}$

In order to check the validity of the assumption that the ratio of first admissions to readmissions remained constant during the study period, the analysis above, based on data for 1976, was also conducted for the years 1970 and 1973 (Fig. A 1). There is some evidence that the ratio of first admissions to readmissions decreased in the later years. This shift would be more compatible with a decreasing incidence rate during the study period than with an increasing incidence rate (see text). However, changes in readmission patterns or other relevant factors (e.g. size and age distribution of the population) could also contribute to this shift. 